\title{
Virological surveillance of influenza virus in acute respiratory infection
}

\author{
Atul J. Sakhiya ${ }^{1, *}$, Kruti Tanna², M.M. Vegad ${ }^{3}$, Pranay K. Shah ${ }^{4}$, Piyush Panchal ${ }^{5}$ \\ ${ }^{1,2}$ Former Resident, ${ }^{3}$ Professor and HOD, ${ }^{4}$ Professor, ${ }^{5}$ Tutor, Dept. of Microbiology, B.J. Medical College, Ahmadabad, \\ Gujarat, India
}

*Corresponding Author:

Email: atulsakhiya87@gmail.com

Received: $8^{\text {th }}$ March, 2018

Accepted: $19^{\text {th }}$ May, 2018

\begin{abstract}
Introduction: Influenza is viral fever with the main symptom of respiratory tract like cough, fever, breathlessness, nasal discharge, sore throat. The influenza affects a large segment of the world population resulting in significant mortality, morbidity and economic loss.

Objective: To monitor the trend of influenza A virus. To know the prevalence of influenza A, H1N1 and seasonal H3 subtypes of influenza virus. To study the seasonal pattern of influenza A virus.

Materials and Methods: This prospective study was carried out in the department of Microbiology, B.J. Medical College, Ahmadabad from January 2014 to December 2014. Surveillance samples were taken as per ILI (Influenza like illness) case definition for out Patient department and SARI (sever acute respiratory syndrome) for indoor patients. Total 614 samples are taken and tested with PCR method.

Result: Out of 614 samples total 201(32.73\%) were positive for influenza. Out of 201 positive samples, $13(2.11 \%)$ were positive for swine $\mathrm{H} 1 \mathrm{~N} 1$ and $11(1.79 \%)$ for seasonal $\mathrm{H} 3,177(28.82 \%)$ were positive for influenza A.

Conclusion: Prevalence of influenza 201(32.73\%). out of this $13(2.11 \%)$ were positive for swine H1N1 and $11(1.79 \%)$ for seasonal H3, 177 (28.82\%) were positive for influenza A. swine H1N1 was common in winter and seasonal H3 was common in late monsoon. swine $\mathrm{H} 1 \mathrm{~N} 1$ and seasonal H3 both are more common in male than female. swine H1N1 is more in >12 age and seasonal $\mathrm{H} 3$ is more common in $<12$ age.
\end{abstract}

Keywords: Influenza A, Swine H1N1, Seasonal H3, Fever, cough, Breathlessness.

\section{Introduction}

Respiratory illnesses due to influenza virus infection are a major cause of morbidity and mortality worldwide. Lower respiratory tract infections are a leading cause of deaths in developing countries and are also the third leading cause of death worldwide. ${ }^{1}$ Globally influenza is responsible for 250,000 to 500,000 deaths annually. ${ }^{1}$ In April 2009, the first case of influenza A H1N1 was reported from Mexico. It was a reassortant between previously circulating swine virus and a Eurasian swine virus and was also called swine origin influenza.

(S-OIV). It spread from person to person and caused a pandemic. ${ }^{2}$ Subsequently, the infection led to spread of disease across 74 countries with 30,000 confirmed cases on June 11, 2009. Total of 214 countries were affected by the pandemic worldwide. ${ }^{1}$

In India, the first case of influenza A H1N1 was reported on May 16, 2009 from Hyderabad. The World Health Organization declared the post pandemic phase on August 10, 2010. The Central and State governments in India had taken the pandemic very seriously and made several unprecedented and innovative interventions including the pandemic preparedness plan. ${ }^{1}$ Of all the viruses that cause respiratory illness, influenza virus plays a dominant role. Influenza viruses are known to cause frequent epidemics and periodic pandemics, and are unique with regard to their antigenic variability, Seasonality and impact on general population. Though children are mainly affected during epidemics, the viruses are also responsible for substantial mortality in the aged and chronically ill persons. ${ }^{4}$ Polymerase chain reaction (PCR) is a technique used to amplify specific regions of DNA from very low levels of starting template DNA. Reverse-transcription PCR (RT-PCR) is an extension of this technique in which template RNA is first reversetranscribed into complementary DNA (cDNA). This cDNA then undergoes amplification by PCR. ${ }^{5}$

Vaccines and antiviral drugs are the two primary methods of implementing influenza prophylaxis.

\section{Materials and Methods}

This prospective study was carried out in the department of Microbiology, B.J. Medical College, Ahmadabad from January 2014 to December 2014.Surviellance samples were taken as per ILI (Influenza like illness) case definition for out Patient department and SARI (sever acute respiratory syndrome) for indoor patients. ${ }^{6}$ Total 614 samples suspected of fever, cough, sore throat, nasal catarrh, shortness of breath were included in this study. Two samples (one nasal and one oropharyngeal/ throat swab) were collected in VTM from the suspected patients of Influenza. Samples were labeled and triple layer packing was done and sample along with request form were transported in cold chain to Virology laboratory (Microbiology department). Sample was proceeding in 
BSC class II.RNA extraction was done by using Kit Content ${ }^{7}$

1. QIAamp mini spin columns

2. Collection tube $2 \mathrm{ml}$

3. Buffer AVL (contains guanidine thiocyanate)

4. Buffer AW1 (concentrate)

\section{RNA Extraction ${ }^{7}$}

Take $1.5 \mathrm{ml}$ micro centrifuged tube add $200 \mu \mathrm{l}$ sample.(1)

\section{I}

LYSIS: $560 \mu 1$ of buffer AVL + carrier RNA, Mix by pulse vortexing for $15 \mathrm{sec}$. Incubate at room temperature $\left(15^{\circ}\right.$ to $\left.25^{\circ} \mathrm{C}\right)$ for 10 minutes in (1)

\section{II}

Add $560 \mu$ of ethanol $(96-100 \%)$ and mix by pulse vortexing for $15 \mathrm{sec}$. in (1)

Add $630 \mu$ l of the solution from (1) to QIAamp mini column ( $2 \mathrm{ml}$ of collection tube), Centrifuged at $6000^{*} \mathrm{~g}(8000 \mathrm{rpm})$ for 1 minute. Place the QIAamp mini column in to a clean $2 \mathrm{ml}$ collection tube, and discard the tube containing the filtrate. Repeat previous step with rest of lysed solution from (1), Place the QIAamp mini column in to a clean $2 \mathrm{ml}$ collection tube.

Carefully open the QIAamp mini column, and add 500 microliter of buffer AW1, Centrifuged at $6000 * \mathrm{~g}$ (8000 rpm) for 1 minute, the QIAamp mini column in to a clean $2 \mathrm{ml}$ collection tube, discard the tube containing the filtrate.

Add 500 microliter of buffer AW2, Centrifuged at $14000 \mathrm{rpm}$ for 3 minute. Discard the old collection tube containing the filtrate. Place the QIAamp mini column in to a clean $1.5 \mathrm{ml}$ collection tube, add 60 microliter of buffer AVE and incubate at room temperature for 1 minute. Centrifuged at $6000^{*} \mathrm{~g}(8000 \mathrm{rpm})$ for 1 minute. Supernatant contains viral RNA.

Primers (oligonucleotides) are complementary sequence of target DNA. Total volume of master mix is 20 microliter for each gene. For each sample, $20 \mu \mathrm{l}$ of master mix and $5 \mu \mathrm{l}$ of RNA extraction is taken for each gene. For Positive control, Negative control, $20 \mu \mathrm{l}$ of
QIAamp Viral RNA Kit.

5. Buffer AW2 (concentrate)

6. Buffer AVE

7. Carrier RNA (poly A)

First RNA extraction is done using all above listed items.

master mix and $5 \mu 1$ of controls were taken, put the plate and process the sample in PCR machine. Thermo cycler raises and lowers the temperature to permit and regulate three steps of PCR (DNA denaturation step, primer anneling step, extension reaction step). ${ }^{8}$ In the PCR machine following cycles are automatically done.

\section{Holding Stage}

1. Step- $150.0^{\circ} \mathrm{C}$ for 30 minutes.

2. Step $-295.0^{\circ} \mathrm{C}$ for 10 minutes.

Cycling Stage ( 45 cycles)

1. Step $-195.0^{\circ} \mathrm{C}$ for 00.15 second

2. Step $-255.0^{\circ} \mathrm{C}$ for 00.30 second.

The whole procedure is repeated in a programmable thermal cycler. Generally, 30-50 thermal cyclers produce millions of copies of the chosen section of the target organism DNA. ${ }^{8}$

After cycles are over PCR will be automatically stop, and we achieve a amplification graph on computer which is attached with machine. Ct value of each sample was detected and if the graph is raised, than consider it as positive. If not, than negative.

\section{Result}

Out of 614 total samples, Total $201(32.73 \%)$ were positive for Influenza. Out of 201 positive samples, 13 $(2.11 \%)$ were for Swine H1N1 and $11(1.79 \%)$ for seasonal $\mathrm{H} 3,177$ (28.82\%) were positive for Influenza A. both Swine H1N1 and seasonal $\mathrm{H} 3$ are more common in male than female. swine H1N1 is more in $>12$ age and seasonal $\mathrm{H} 3$ is more common in $<12$ age. swine $\mathrm{H} 1 \mathrm{~N} 1$ is mostly occurs in winter and seasonal $\mathrm{H} 3$ is more common in late monsoon. (Fig. 1 to 3 )

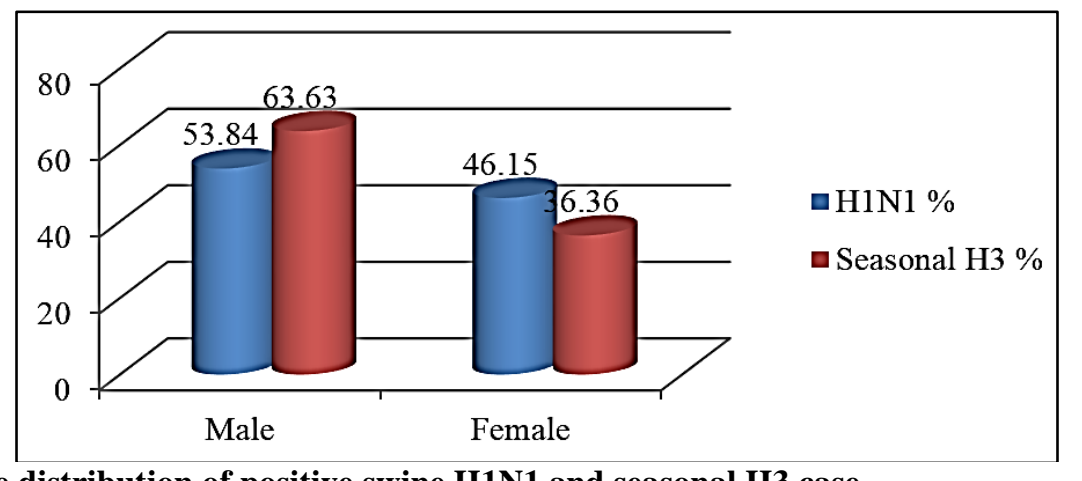

Fig. 1: Gender wise distribution of positive swine H1N1 and seasonal H3 case

The probable reason for predilection of male sex may be due to greater mobility, susceptibility and exposure to infection and also this age group consists of economically productive mobile population, travelling more for various reasons and most susceptible to 
exposure to infection, so they get exposed to virus easily and get infected easily. ${ }^{11}$

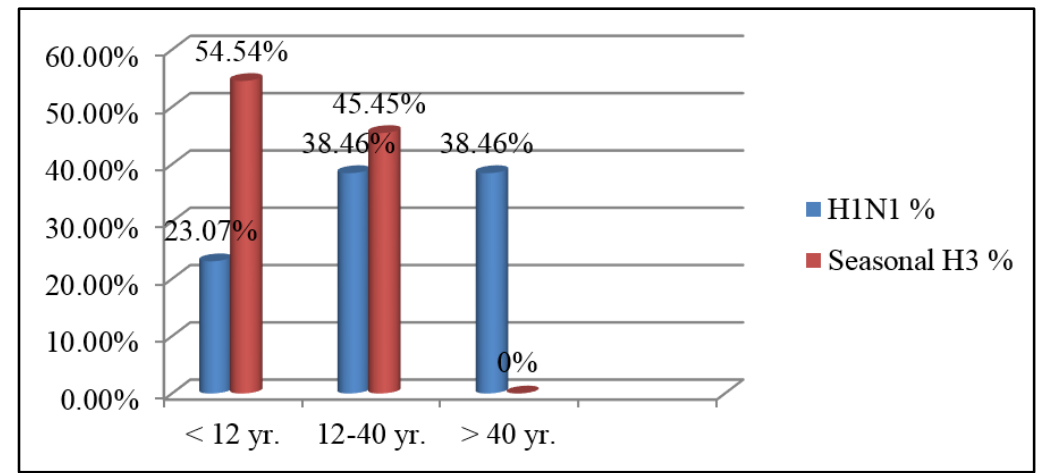

Fig. 2: Age wise distribution of positive swine H1N1 and seasonal H3 case

Swine H1N1 prevalence is high in elder people may be due to immunity is tapering at this age and so this people are more prone to infection.

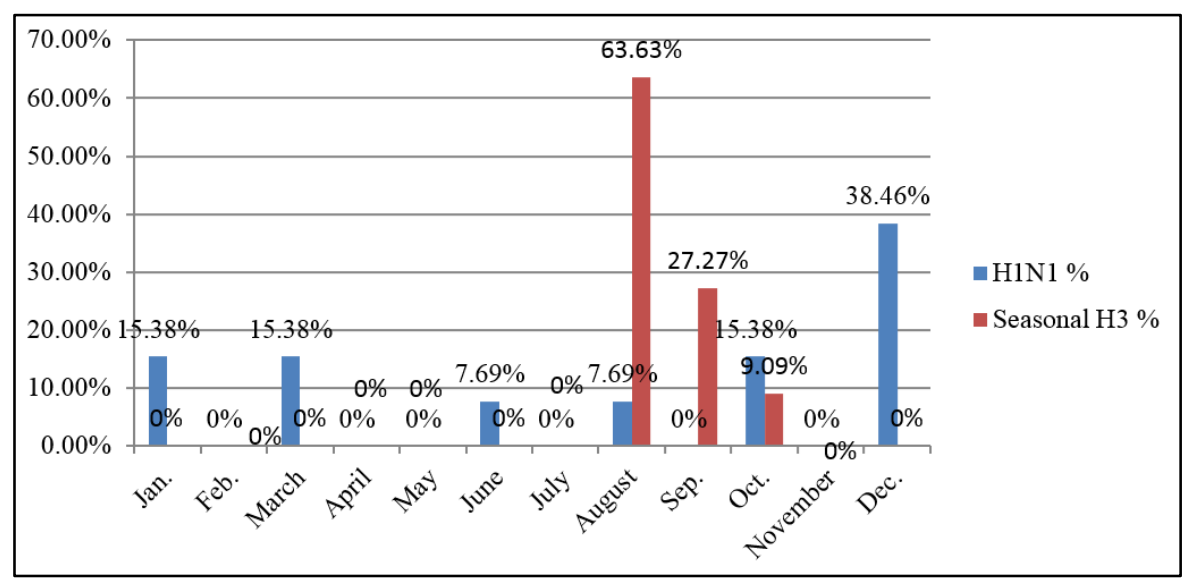

Fig. 3: Month wise distribution of positive swine H1N1 and seasonal H3 case.

Prevalence of swine $\mathrm{H} 1 \mathrm{~N} 1$ in winter mainly because of this virus can survive and multiply more in cold \& dry environment. Seasonal H3 also generally occur in winter but here it may be due to some mutation, it occur in late monsoon. The reason for monsoon Predilection might be due to climatic factors such as relative humidity, rainfall and differences in temperature may cause the rapid shedding of this virus. $^{13}$

\section{Discussion}

Table 1: Comparison of our study with other influenza surveillance studies

\begin{tabular}{|l|c|c|}
\hline \multicolumn{1}{|c|}{ Study } & Positivity of Swine H1N1 (\%) & Positivity for seasonal H3 (\%) \\
\hline Our study & $2.11 \%$ & $1.79 \%$ \\
\hline $\begin{array}{l}\text { B. L. Rao, K. Banerjee et al, } \\
\text { In Pune, India, 1978-1990. }\end{array}$ & $0.9 \%$ & $1.16 \%$ \\
\hline
\end{tabular}

In our study positivity of Swine H1N1 (2.11\%) is comparable with the study of B.L. Rao et al. Difference in positivity with B.L. Rao et al might be due to difference in strain and different in geographical area. Seasonal $\mathrm{H} 3$ positivity in our study $(1.79 \%)$ is well correlated with the study of B.L. Rao et al.
Table 2: Ratio of male and female in positive Swine H1N1 patients

\begin{tabular}{|l|c|c|}
\hline \multicolumn{1}{|c|}{ Study } & Male\% & Female\% \\
\hline Our study & $53.84 \%$ & $46.15 \%$ \\
\hline $\begin{array}{l}\text { Dr. Tripurari Kumar } \\
\text { et al, Punjab. }\end{array}$ & $54.1 \%$ & $45.9 \%$ \\
\hline
\end{tabular}


In our study prevalence of Swine H1N1 is more in male compared to female which is well correlated with study of Dr. Tripurari Kumar, et al.

Table 3: Ratio of male and female in seasonal $\mathrm{H3}$ Positive patients

\begin{tabular}{|l|c|c|}
\hline \multicolumn{1}{|c|}{ Study } & Male\% & Female\% \\
\hline Our study & $63.63 \%$ & $36.36 \%$ \\
\hline Susanna Esposito et al. ${ }^{10}$ & $60.1 \%$ & $39.9 \%$ \\
\hline
\end{tabular}

In our study prevalence of seasonal $\mathrm{H} 3$ is more in male compared to female which is well correlated with study of Susanna Esposito et al.

Our study shows that prevalence of Swine H1N1 in pediatric age group (23.07\%) is lowest, followed by $12-40$ years age group $(38.46 \%)$, followed by aged $>40$ years $(38.46 \%)$. The study of Arvind Chandora et a ${ }^{11}$ also shows lowest prevalence in 0-20 years and nearly equal prevalence in middle age and $>40$ years of age group. Difference in the prevalence in pediatric age group is due to selection of different age group in the study. Study done by M.P. Tambe et $\mathrm{al}^{12}$ shows similar prevalence $(23.94 \%)$ in $(<10$ year) pediatric patients.

In our study prevalence of seasonal $\mathrm{H} 3$ is highest in $<12$ years age group (54.54\%) followed by middle age group $(45.45 \%)$ and no sample positive in age group $>40$ years. The study done by Sam Peter et $\mathrm{al}^{13}$ in Kerala shows relatively higher prevalence in middle age group $(47.91 \%)$ than pediatric age group $(43.75 \%)$ and lowest prevalence in $>45$ years of age group $(8.33 \%)$. This might be due to difference in geographical area and differences in sample size selected.

In our study, Fig. 3 shows prevalence of Swine H1N1 is highest in December month $(38.46 \%)$. The study done by Archana Choudhry et $\mathrm{al}^{1}$ in 2009 in Delhi (29.45\%) shows highest no. of cases in December month. This was an alarming signal as we faced a big epidemic of H1N1 in 1st quarter of 2015. Seasonal H3 shows maximum number of cases during August, followed by September, followed by October month. No cases detected in other months of the year.

\section{Conclusion}

Influenza infections cause substantial morbidity and mortality every year. Influenza surveillance has focused on virological monitoring and collection of specimens to guide vaccine strain selection. Continuous monitoring would be required for early detection of any antigenic variants to understand the seasonality and analyses factors such as temperature and rainfall in the transmission of influenza viruses. Implementation of a sentinel network reinforces the importance of a national strategy for the control and prevention of Influenza.

\section{References}

1. Choudhry Archana, Singh Supriya, Khare Shashi, Rai Arvind, Emergence of pandemic 2009 influenza A H1N1, India. Indian J Med Res. 135, April 2012, p. 534-537.

2. Anantnarayan and Paniker, Text book of microbiology, 9th edition, Chennai, Orient Longman; page no.496-504.

3. Rao B.L., Banerjee K., influenza surveillance in Pune, India, 1978-1990. Bulletin of WHO. 1993;71(2):177-181.

4. Roy S., Patil D., Dahake R., Mukherjee S., Athlekar SV., Deshmukh RA., Chowdhary A., Prevalence of influenza virus among the pediatric population in Mumbai during 2007-2009. Indian Journal of Medical Microbiology. 2012,30(2):155-8.

5. WHO Global Influenza Surveillance Network, Manual for the laboratory diagnosis and virological surveillance of Influenza, 2011, Page-84.

6. WHO, Global epidemiological surveillance standard for Influenza, 2013.Page.14.

7. QIAamp® Viral RNA Mini Handbook, 3rd edition, April 2010, page.3-10.

8. Chakraborty P., textbook of microbiology, 3rd edition, 2013, page. 563.

9. Kumar Tripurari, Bhatia Deepak, Kumar Rajesh, Lakshmi PVM, Narain J. P., Dikid Tanzin; Risk Factors for Death Among Hospitalized Influenza A (H1N1) Patients in Punjab, India; India EIS conference, November 2013, Page. 9-13.

10. Esposito Susanna et al, clinical and socioeconomical impact of different types and subtypes of seasonal influenza viruses in children during influenza 2007/2008 and 2008/2009.

11. Chandora Arvind, Khatri P. K., Meena Saroj, Bora Archana, Rathore Laxmi and Sharma Niranjan, Study of Swine Flu Virus Re-Emergence in Western Rajasthan Jodhpur in Reference to Different Age Groups (Risk Factor), Int J Curr Microbiol App Sci. 2015;4(7):352-358.

12. Tambe M.P., Parande M., Jamkar A.V., Pardesi R.R., Baliwant K. An Epidemiological Study of Confirmed H1N1 Admitted Cases in an Infectious Disease Hospital, Pune, JKIMSU. 2012;1:No. 2.

13. Peter Sam, Balakrishnan Anukumar, Potdar Varsha A, Chadha Mandeep S, Jadhav Santosh M, An outbreak of influenza A(H3N2) in Alappuzha district, Kerala, India, in 2011. J Infect Dev Ctries. 2015;9(4):362-367.

How to cite this article: Sakhiya AJ, Tanna K, Vegad MM, Shah PK, Panchal P. Virological surveillance of influenza virus in acute respiratory infection. Indian J Microbiol Res. 2018;5(3):299302. 